\title{
BUILDING RELIGIOUS GENERATION THROUGH WINNER SCHOLARSHIP PROGRAM IN ICD BUAH BATU BANDUNG CITY
}

\section{MEMBANGUN GENERASI RELIGIUS MELALUI PROGRAM BEASISWA JUARA DI ICD BUAHBATU KOTA BANDUNG}

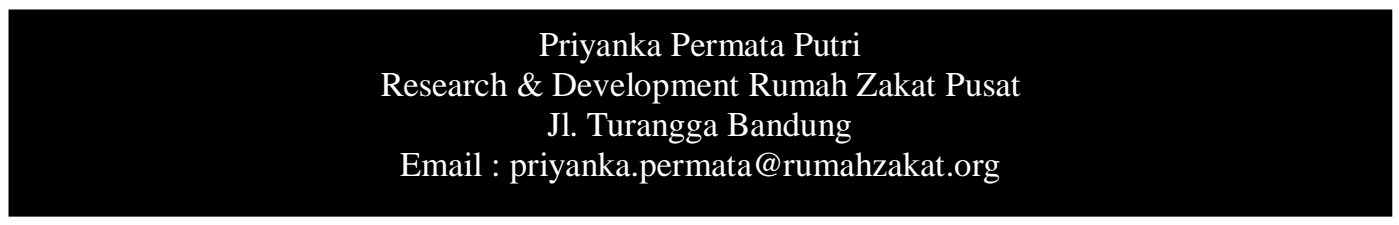

Abstract, 'Beasiswa Juara' program through regular development of the science of religion in ICD (Integrated Community Development) Buahbatu Bandung a positive impact on 'Anak Juara' with demonstrated by the presence of beneficiaries (PM) and there are success stories of one PM who shows positive impact on his life. The research objective was to determine the success of the development program 'Beasiswa Juara' grantee 'Anak Juara' in creating a religious generation. This research is descriptive with the method used is the study of literature, by looking at the secondary data from the achievements of the program implemented Rumah Zakat and look of ICD profile.

Results from this research that the grantee children who follow a routine training activities of religious knowledge has a positive influence to be applied in everyday life so as to create a religious person, it is seen from the changes in children's behavior on the success story of one of the PM.

Keywords: 'Rumah Zakat', 'Beasiswa Juara', Religious, Buahbatu, Bandung.

Abstrak, Program Beasiswa Juara melalui pembinaan rutin tentang ilmu agama di ICD (Intergrated Community Development) atau lebih dikenal dengan desa binaan Buahbatu Kota Bandung memberikan dampak positif bagi anak juara dengan ditunjukkan oleh kehadiran Penerima Manfaat (PM) dan terdapat success story dari salah satu PM yang memperlihatkan dampak positif bagi kehidupannya. Tujuan penelitian adalah mengetahui keberhasilan program pembinaan anak juara penerima Beasiswa dalam menciptakan generasi religius. Penelitian ini merupakan penelitian deskriptif dengan metode yang digunakan yaitu studi literatur, dengan melihat data sekunder dari capaian program yang diimplementasikan Rumah Zakat dan melihat dari profil ICD.

Hasil dari penelitian ini yaitu siswa penerima Beasiswa Juara yang mengikuti kegiatan pembinaan rutin tentang ilmu agama ini telah memberikan pengaruh positif untuk diterapkan di kehidupan sehari-hari sehingga tercipta pribadi yang religius, hal ini terlihat dari perubahan perilaku anak juara pada success story salah satu PM.

Kata Kunci : Rumah Zakat, Beasiswa Juara, Religius, Buahbatu, Bandung.

\section{A. PENDAHULUAN}

Pelajar merupakan masyarakat yang berakhlak mulia, generasi jujur, cerdas, kreatif, mandiri, maju, penerus bangsa yang harus dibimbing sejahtera, setia kawan, dan berkeadilan oleh seseorang berpengetahuan lebih. juga berupaya meningkatkan kualitas Hal ini bertujuan untuk membantu Sumber Daya Manusia di berbagai mewujudkan nilai dan kualitas bidang. Kondisi anak bangsa saat ini,

11 Membangun Generasi Religius Melalui Program Beasiswa Juara Di ICD Buahbatu Kota Bandung 
Edutech, Tahun 15, Vol.15, No.1, Februari 2016

sangat menentukan kondisi keluarga, hidup di dunia dan di akhirat" masyarakat dan bangsa di masa depan.

Menurut S.C Utami Munandar (Sulaiman, 1993)

Pengertian di atas menunjukkan (1995), perkembangan kecerdasan, bahwa peran pendidikan agama islam kreativitas dan kemandirian berkaitan sangat penting di kehidupan sehari-hari erat dan saling menguatkan, yang akan yang selayaknya harus ditanamkan menentukan kualitas manusia sejak dini. Apabila pengetahuan agama pembangunan di masa depan. dimiliki oleh setiap insan muda di Perkembangan tersebut memerlukan Indonesia, maka akan tercipta generasi stimulus yang baik agar SDM di masa depan pun akan lebih baik dengan yang religius yang akan menjadi kekuatan tersendiri untuk membangun mewujudkan generasi yang religius. Pemberian stimulus untuk menciptakan generasi yang religius dibutuhkan bimbingan secara terus menerus agar motivasinya tetap terjaga.

Pendidikan keagamaan bertujuan untuk perubahan yang diinginkan, baik pada tingkah laku individu pada kehidupan pribadinya, kehidupan masyarakat, dan alam sekitar maupun pada proses pendidikan dan pengajaran itu sendiri sebagai suatu aktifitas asasi dan sebagai proporsi di antara profesi asasi dalam masyarakat (Syaiban, 1979, hlm. 399). Sedangkan menurut al-Ghazali menyatakan bahwa "tujuan umum pendidikan Islam tercermin dalam dua segi, yaitu; 1. insan purna yang bertujuan mendekatkan diri kepada Allah SWT, 2. insan purna yang bertujuan mendapatkan kebahagiaan negeri di masa depan. Namun, melihat berbagai perkembangan jaman dan berbagai bentuk penyimpangan generasi muda saat ini akan menjadi suatu tantangan dalam mewujudkan generasi religius tersebut.

Banyak penyimpangan generasi muda saat ini, seperti penyalahgunaan narkoba. KPAI (Komisi Perlindungan Anak Indonesia) yang bekerja sama dengan BNN (Badan Narkotika Nasional) mengungkapkan bahwa pada tahun 2015 terdapat $20 \%$ dari pelaku penyalahgunaan narkoba didominasi oleh anak. Angka ini terus meningkat tiap tahun dan semakin mengkhawatirkan.

Bentuk penyimpangan remaja lainnya yaitu aborsi, hasil suervei yang dilakukan Komnas Perlindungan Anak (Ado, 2010) menyebutkan sebanyak 
Edutech, Tahun 15, Vol.15, No.1, Februari 2016

21,2 persen remaja di Indonesia pendidikan yang ditempuh. Beasiswa mengaku pernah melakukan aborsi dapat diberikan oleh lembaga karena hubungan di luar nikah dengan pemerintah, perusahaan, yayasan atau teman dekatnya. Akibatnya, 8 ribu atau instansi-instansi yang lain.

$57,1 \%$ kasus HIV/AIDS terjadi pada

Menurut Undang-Undang Nomor remaja dengan $37,8 \%$ terinfeksi 20 Tahun 2003 tentang Sistem melalui hubungan seks yang tidak aman dan $62,2 \%$ terinfeksi melalui penggunaan narkoba jarum suntik.

Masih banyak penyimpangan yang dilakukan oleh generasi muda kita, mulai dari tindak kekerasan, pencurian, penyerangan, tawuran pelajar, mengkonsumsi alkohol serta berbagai bentuk lain yang melanggar norma dan nilai-nilai agama.

Melihat fakta-fakta tersebut, perlu adanya solusi dalam membimbing generasi penerus ini agar tidak menjadi generasi perusak pribadi bangsa. Rumah Zakat (RZ) berperan aktif Beasiswa Juara merupakan dalam memberikan stimulus kepada generasi muda agar memiliki akhlak mulia melalui berbagai programnya, salah satunya yaitu pembinaan bagi penerima beasiswa yaitu bagi anakanak juara RZ.

Beasiswa itu sendiri maknanya pemberian berupa bantuan keuangan yang diberikan kepada perorangan, mahasiswa, atau pelajar yang Pendidikan Nasional, Bab V pasal 12 (1.c), pasal itu menyebutkan bahwa setiap peserta didik pada setiap satuan pendidikan berhak mendapatkan beasiswa bagi yang berprestasi yang orang tuanya tidak mampu membiayai pendidikannya. Mahalnya biaya pendidikan bagi sebagian masyarakat membuat RZ tergerak untuk ikut serta memberikan bantuan biaya pendidikan bagi yang membutuhkan yang bersinergi dengan Sistem Pendidikan Nasional melalui program Beasiswa Juara.

program pemberian beasiswa disertai kegiatan pembinaan berkala untuk siswa SD, SMP, SMA, dan Mahasiswa dari keluarga kurang mampu. Beasiswa ini juga bertujuan untuk membantu pelajar yang berbakat dan berprestasi dari kalangan ekonomi kurang mampu agar dapat melanjutkan pendidikan ke jenjang yang lebih tinggi. Program digunakan demi keberlangsungan

13 Membangun Generasi Religius Melalui Program Beasiswa Juara Di ICD Buahbatu Kota Bandung 
di berbagai wilayah ICD, diantaranya yaitu di ICD Buahbatu Kota Bandung.

1. Metode Penelitian

Penelitian ini merupakan penelitian deskriptif dengan metode yang digunakan yaitu studi literatur, dengan melihat data sekunder dari capaian program yang

diimplementasikan oleh Rumah Zakat, dan melihat dokumentasi perkembangan dari ICD Buahbatu Kota Bandung.

\section{B. HASIL DAN PEMBAHASAN}

Religiusitas dapat berfungsi sebagai sebuah faktor protektif yang dapat mencegah individu untuk melakukan tindakan-tindakan yang beresiko. Agama selain sebagai faktor yang melindungi dari perilaku antisosial juga memberikan motivasi, sumber kekuatan psikologis, cara berperilaku atau dukungan sosial yang penting untuk menghindari godaan melakukan perilaku anti sosial.

Dari penelitian mengenai "Dampak Kurikulum dan Model Pembelajaran terhadap Religiusitas, Spiritualitas, dan Perilaku Remaja", terdapat hasil penelitian bahwa hasil analisis data menggunakan t-test ditemukan bahwa skor rata-rata religiusitas siswa sekolah berbasis
Islam $(M=3.84, S D=0.83)$ lebih tinggi dari skor rata-rata religiusitas siswa sekolah berkurikulum nasional $(M=3.31, S D=0.62) t=9.069, p<$ 0.001. Hasil ini menunjukkan terdapat perbedaan yang signifikan dalam religiusitas antara siswa dari sekolah dengan kurikulum bermuatan agama dan sekolah berkurikulum nasional.

Melihat hasil penelitian tersebut, RZ berinisiatif membangun Sekolah Juara gratis bagi anak kurang mampu yang berbasis Multiple Intelligence dan bernuansa religius dengan memberikan pembinaan agama secara rutin setiap pekan. RZ juga memberikan beasiswa kepada siswa di luar Sekolah Juara yang bernama program Beasiswa Juara.

RZ melalui program Beasiswa Juara berupaya memberikan dukungan pendidikan formal di Sekolah Juara binaan RZ maupun non formal untuk mencetak generasi Juara di Indonesia. Sepanjang tahun 2015, RZ bersama para donatur dan mitra telah memberikan beasiswa bagi 19.906 anak asuh di 723 wilayah ICD (Integrated Community Development) atau lebih dikenal dengan desa binaan, termasuk di ICD Buahbatu Kota Bandung.

14 Membangun Generasi Religius Melalui Program Beasiswa Juara Di ICD Buahbatu Kota Bandung 
Kondisi agama di ICD Buahbatu Kota Bandung pada umumnya mayoritas beragama Islam serta taat menjalankan ibadah, namun ada sebagian kecil warga yang beragama non Muslim. Sedangkan kondisi pendidikannya, tidak semuanya sadar akan pentingnya pendidikan, terutama masyarakat kurang mampu. Masih terdapat anak yang berhenti sekolah sampai jenjang Sekolah Dasar, dengan dalih membantu orang tuanya mencari rezeki.

Kondisi yang masih banyaknya anak yang berhenti sekolah di tingkat SD, menjadikan dasar dalam Juni 2015 :

Tabel 1.1

Data Penerima Manfaat (PM) Program Beasiswa Juara di ICD Buahbatu Kota Bandung

\begin{tabular}{clc}
\hline No. & \multicolumn{1}{c}{ Bulan } & $\begin{array}{c}\text { Jumlah } \\
\text { PM }\end{array}$ \\
\hline $\mathbf{1}$ & Juli 2014 & 39 \\
$\mathbf{2}$ & Agustus 2014 & 43 \\
$\mathbf{3}$ & September 2014 & 40 \\
$\mathbf{4}$ & Oktober 2014 & 35 \\
$\mathbf{5}$ & Nopember 2014 & 35 \\
$\mathbf{6}$ & Desember 2014 & 29 \\
$\mathbf{7}$ & Januari 2015 & 31 \\
$\mathbf{8}$ & Februari 2015 & 28 \\
$\mathbf{9}$ & Maret 2015 & 29 \\
$\mathbf{1 0}$ & April 2015 & 28 \\
\hline
\end{tabular}

15 Membangun Generasi Religius Melalui Program Beasiswa Juara Di ICD Buahbatu Kota Bandung 
Edutech, Tahun 15, Vol.15, No.1, Februari 2016

$\begin{array}{lll}\mathbf{1 1} & \text { Mei } 2015 & 29 \\ \mathbf{1 2} & \text { Juni } 2015 & 27\end{array}$

Pada Tabel 3.1 di atas terlihat sedikit penurunan jumlah PM, pada bulan Agustus 2014 terdapat 43 anak juara, kemudian jumlah PM relatif mengalami penurunan yang terlihat pada bulan juni 2015 terdapat 27 anak juara penerima Beasiswa Juara. Walaupun mengalami penurunan, dengan pembinaan rutin ini anak juara diharapkan mampu menanamkan hal yang dipelajari dalam pembinaan tersebut ke kehidupan sehari-hari. Hal tersebut bisa dilihat dari success story penerima manfaat salah satunya yaitu Ikbalul Gina.

Iqbalul Gina merupakan anak ke-2 dari 7 bersaudara, berasal dari keluarga kurang mampu. Sekarang Iqbal duduk di kelas 6 SD. Kakaknya Iqbal hanya bersekolah sampai tingkat SD, dan tidak melanjutkan ke jenjang SMP karena terbentur dengan biaya. Dengan terpaksa harus putus sekolah dan membantu orangtuanya mencari nafkah. Dalam keterbatasan ekonomi Iqbal terus bersemangat menuntut ilmu. Iqbal sangat rajin mengikuti kegiatan yang diadakan oleh RZ, baik kegiatan pembinaan maupun kegiatan yang lainnya. Setelah mendapatkan binaan Iqbal sudah mampu membaca AlQur'an dengan baik, serta memiliki hafalan surat-surat pendek yang cukup baik.

Dari success story tersebut terlihat bahwa pembinaan yang diberikan bagi anak juara penerima Beasiswa Juara ini berpengaruh positif bagi PM, khususnya dalam ilmu agama Islam. Apabila program ini dilaksanakan dengan konsisten dan perkembangan penyebaran PM semakin baik maka akan tercipta generasi yang religius sebagai pribadi bangsa di masa depan.

Adapun daftar nama anak juara Penerima Manfaat (PM) Beasiswa Juara di ICD Buahbatu Kota Bandung yaitu sebagai berikut :

Tabel 1.2

Daftar Nama Anak Juara Penerima Beasiswa Juara di ICD Buahbatu Kota Bandung Per Juni 2015

No. Nama

16 Membangun Generasi Religius Melalui Program Beasiswa Juara Di ICD Buahbatu Kota Bandung 


\begin{tabular}{ll}
\hline $\mathbf{1}$ & Andri Ramdani \\
$\mathbf{2}$ & Asep Roni \\
$\mathbf{3}$ & Burhan \\
$\mathbf{4}$ & Dendi Rahmat \\
$\mathbf{5}$ & Diana Citra \\
$\mathbf{6}$ & Dina Fauji \\
$\mathbf{7}$ & Ikbalul Gina \\
$\mathbf{8}$ & Ilham Nazril Muksi \\
$\mathbf{9}$ & Komalasari \\
$\mathbf{1 0}$ & Lia Daria \\
$\mathbf{1 1}$ & M. Ridwan Firdaus \\
$\mathbf{1 2}$ & Meylani Dwi Dipradja \\
$\mathbf{1 3}$ & Neng Rismayanti \\
$\mathbf{1 4}$ & Nur Intan \\
$\mathbf{1 5}$ & Pajar \\
$\mathbf{1 6}$ & Rafa Salsadhiantoro \\
$\mathbf{1 7}$ & Rahma Fadillah \\
$\mathbf{1 8}$ & Redy Rian \\
$\mathbf{1 9}$ & Rido Juliansyah \\
$\mathbf{2 0}$ & Riznaldi Muhammad \\
$\mathbf{2 1}$ & Royadi \\
$\mathbf{2 2}$ & Ryan Adiguna \\
$\mathbf{2 3}$ & Siti Wulansari \\
\hline
\end{tabular}

Terselenggaranya program donatur yang telah mendonasikan Beasiswa Juara tidak terlepas dari sebagian hartanya kepada RZ. Jumlah 
donatur yang berdonasi pada program Beasiswa Juara ini terus bertambah setiap tahunnya, begitu pula dengan nominal yang diperoleh.

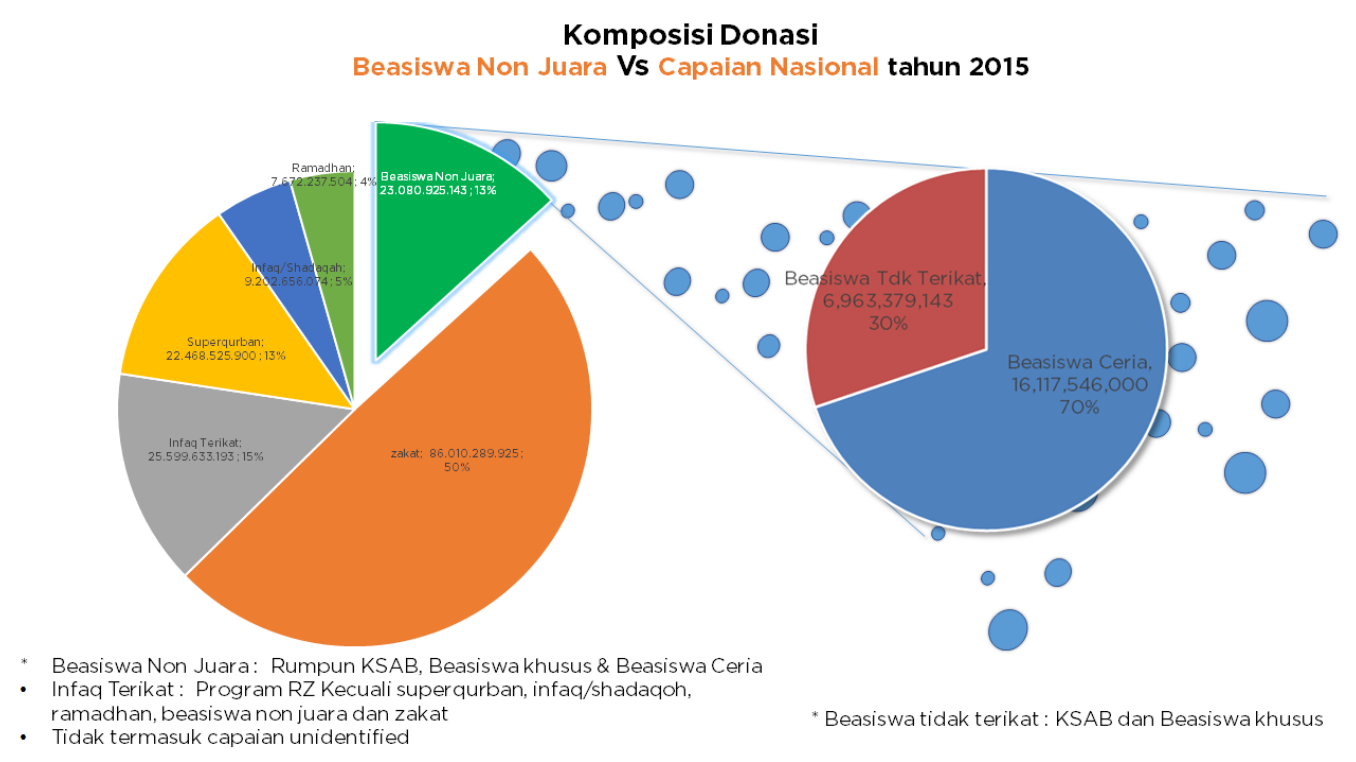

\section{Gambar 1.1}

\section{Komposisi Donasi}

Melihat dari komposisi dana untuk ceria sebesar 70\%. Beasiswa Non Juara program beasiswa ini terdapat $13 \%$ dari terdiri dari rumpun KSAB, Beasiswa seluruh dana yang terkumpul di RZ. khusus dan Beasiswa Ceria, sedangkan Dari $13 \%$ tersebut terinci bagi beasiswa Beasiswa tidak terikat yaitu KSAB dan tidak terikat sebesar 30\% dan beasiswa Beasiswa Khusus.

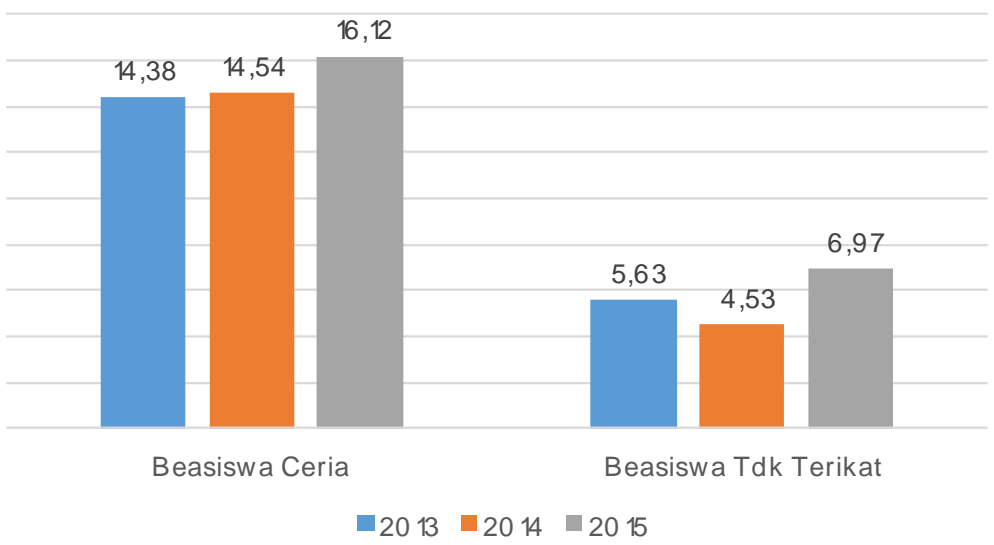

Grafik 1.2

\section{Jumlah Donatur Berdonasi}

18 Membangun Generasi Religius Melalui Program Beasiswa Juara Di ICD Buahbatu Kota Bandung 
Edutech, Tahun 15, Vol.15, No.1, Februari 2016

Jumlah Donatur Berdonasi

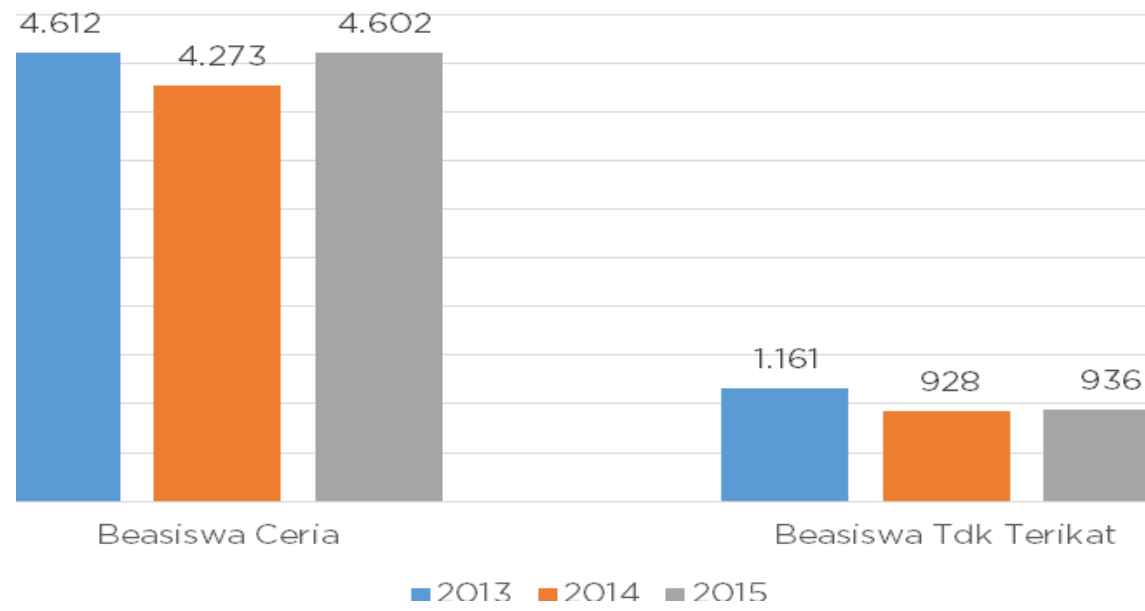

Grafik 1.1

\section{Jumlah Donasi (dalam Milyar)}

Pada Grafik 3.1 di atas dengan semakin tersebar di seluruh memperlihatkan bahwa terdapat wilayah Indonesia.

peningkatan jumlah donasi tiap C. KESIMPULAN

tahunnya baik dari jenis beasiswa ceria Program Beasiswa Juara melalui maupun beasiswa tidak terikat. Capaian pembinaannya menjadi sarana untuk donasi beasiswa ceria pada tahun 2015 mencetak generasi penerus yang meningkat $11 \%$ dari $14,54 \mathrm{M}$ (pada religius dengan pembinaan rutin bagi tahun 2014) menjadi 16,12 M. penerima manfaat secara konsisten agar Sedangkan beasiswa tidak terikat pada anak-anak juara ini memiliki karakter tahun 2015 meningkat $54 \%$ dari 4,53 berakhlak mulia bagi masa depan M (pada tahun 2014) menjadi 6,97 M. kelak.

Dari Grafik 3.2 donatur yang berdonasi

Penulis menyampaikan ucapan pada tahun 2015 sebanyak 4.602 terimakasih kepada bagian Program donatur.

Program beasiswa ini diharapkan Rumah Zakat yang telah memberikan dapat menciptakan generasi yang kepada penulis sebagai referensi dalam berpendidikan dengan memiliki akhlak menyusun artikel ilmiah ini. yang religius dan bisa bermanfaat bagi D. DAFTAR PUSTAKA masyarakat, bangsa dan agama kelak 
Edutech, Tahun 15, Vol.15, No.1, Februari 2016

.... Monthly Report : Indonesia Juara

Foundation. Indonesia Juara

Foundation. Bandung : 2015.

Herlina,dkk. Dampak Kurikulum dan

Model Pembelajaran terhadap

Religiusitas, Spiritualitas, dan

Perilaku Remaja. [Online]

Tersedia

http://ejournal.upi.edu/index.php/

edutech/article/view/1388/966

(diakses tanggal 13 April 2016

Pkl. 13.07 WIB)

Novitaningtyas, R. Hubungan Antara

Pola Asuh dengan Delinkuensi

Remaja. [Online]. Tersedia :

https://www.academia.edu/73110

52/hubungan_antara_pola_asuh_

dengan_delinkuensi_remaja

(diakses tanggal 13 Juli 2015 Pkl.

1518 WIB)

Setyawan, Davit. Kerja Bareng BNN

Sulut Bareng KPAI, 20 Persen

Pelaku Penyalahguna Narkoba

Didominasi Anak. [Online].

Tersedia

http://www.kpai.go.id/berita/kerja

-bareng-bnn-sulut-bareng-kpai-

20-persen-pelaku-penyalahguna-

narkoba-didominasi-anak/

(diakses tanggal 13 Juli 2015 Pkl.

1418 WIB)

Subakti, Ganjar Eka. (2015). Pengaruh
Latar Belakang Pendidikan dan Organisasi Intra Kampus terhadap Akhlak Mahasiswa Universitas Pendidikan Indonesia. S2 Thesis, Universitas Pendidikan Indonesia. [Online]. Tersedia http://repository.upi.edu/14347/ (diakses tanggal 13 Juli 2015 Pkl.14.13 WIB)

20 Membangun Generasi Religius Melalui Program Beasiswa Juara Di ICD Buahbatu Kota Bandung 